\title{
Strengthening Integration of Communication Theory into Entertainment-Education Practice: Reflections from the La Peor Novela Case Study
}

\author{
Rafael Obregon, Jessica Wendorf Mubamad, \\ and Charlotte Lapsansky
}

The need to bridge the gap between theory and practice is often at the heart of discussions about the role of communication in promoting social and behavioral change and advancing development outcomes. Over the past several years, scholars and practitioners in Communication for Development (C4D) and Social and Behavior Change Communication (SBCC) have made considerable progress in strengthening the integration of theory into the practice of $\mathrm{C} 4 \mathrm{D} / \mathrm{SBCC}$ programmatic design, implementation, and evaluation. This is illustrated by the definitions of C4D/

R. Obregon $(\bowtie) \bullet$ C. Lapsansky

UNICEF, New York, NY, USA

e-mail: robregon@unicef.org; clapsansky@unicef.org

J. W. Muhamad

Florida State University, Tallahassee, FL, USA

e-mail: jw.muhamad@cci.fsu.edu

(C) The Author(s) 2021

L. B. Frank, P. Falzone (eds.), Entertainment-Education Behind the

Scenes, https://doi.org/10.1007/978-3-030-63614-2_9 
SBCC currently used among leading development institutions, which increasingly emphasize theory and evidence-based approaches. For instance, the United Nations Children's Fund (UNICEF), one of the leading global development agencies in the use of C4D strategies, defines $\mathrm{C} 4 \mathrm{D}$ as "an evidence-based process that is an integral part of programmes and utilizes a mix of communication tools, channels and approaches to facilitate dialogue, participation and engagement with children, families, communities, and networks for positive social and behaviour change in both development and humanitarian contexts" (UNICEF, 2018, p. 8). The Johns Hopkins University Health Communication Capacity Collaborative (n.d.) emphasizes four key characteristics of SBCC-systematic, evidence-based, participatory, and focused on strengthening capacity - and explicitly states that it uses theory to frame program design.

While SBCC theories generally play an important role in the design of communication strategies in development programs, many of which feature entertainment-education (EE) components (Brown, 2013; Piotrow, Kincaid, Rimon, \& Rinehart, 1997; Singhal \& Rogers, 1999), there tends to be greater emphasis on using social and cognitive theory to inform interventions. Studies of EE have frequently described the effects of specific messages within an EE intervention on individuals' social interactions and/or behaviors; the influence of communication theory within EE interventions is less clearly articulated (Cardey, Garforth, Govender, \& Dyll-Myklebust, 2013; Makanweni \& Salawu, 2018) and the role of the broader narrative structure or impacts of storytelling is often overlooked. There are several communication theories that explore how individuals process narratives and explain how EE leads to attitudinal, behavioral, or social change (Moyer-Gusé, 2008). Petraglia (2007) captures this point in relation to health communication:

Health communication strategies that rely overtly on storytelling, such as "entertainment-education" (EE), sidestep narrative as a conceptual framework. While the literatures of behavior change communication and EE (in the form of soap operas, novels, theatre, ballads, serialized comic strips, fotonovelas, etc.) frequently allude to social-cognitive theory and role modeling as proposed by Albert Bandura (1986), the fact that role models are characters whose behavior is only understood within the context of a story goes largely unremarked and unexplored. (pp. 494) 
Other scholars have raised similar concerns. Tufte (2008) stated that organizations leading EE interventions in health and development communication could benefit from more in-depth exploration of the linkages between communication theory, especially media and audience theory, and the intended behavior change outcomes. Sood, Riley, and Alarcon (2017) have argued that there is a need to "continue to unpack the role of narrative engagement/transportation/emotional involvement to understand further how and why narratives matter" (p. 32). This issue is of critical importance to development practice. To the extent that communication theory does not properly or sufficiently inform EE, its effectiveness can be limited.

Our point of departure for this chapter is that the effectiveness of EE interventions can be enhanced through a more explicit theoretical foundation. We argue that this integration of theory into practice needs to include more emphasis on communication theory alongside the more traditionally invoked social and cognitive theories. We explore these issues through the lens of an EE intervention led and implemented by the United Nations Children's Fund (UNICEF) in the Dominican Republic to promote prevention of child marriage by addressing unequal gender norms.

\section{UNICEF's Development Agenda And the Role OF $\mathrm{C} 4 \mathrm{D} / \mathrm{SBCC}$}

Anchored in the Convention on the Rights of the Child (UN Commission on Human Rights, 1990; UNICEF, 2019), UNICEF's Strategic Plan for the 2018-2021 period has the overarching goal to drive results for the most disadvantaged children and young people across five goal areas (UNICEF, 2018): (1) survival and development; (2) learning; (3) protection from exploitation and violence; (4) living in a clean and safe environment; and (5) having an equitable chance in life. The goals are tied to specific results, prioritizing gender equality and humanitarian dimensions (see Fig. 9.1). The Strategic Plan describes specific change strategies that UNICEF values. One of these change strategies is C4D, and it specifically engages local communities, adolescents, and young people to promote social and behavior change.

UNICEF C4D work is guided by the social-ecological model, a framework that facilitates understanding the complex effects of personal and 


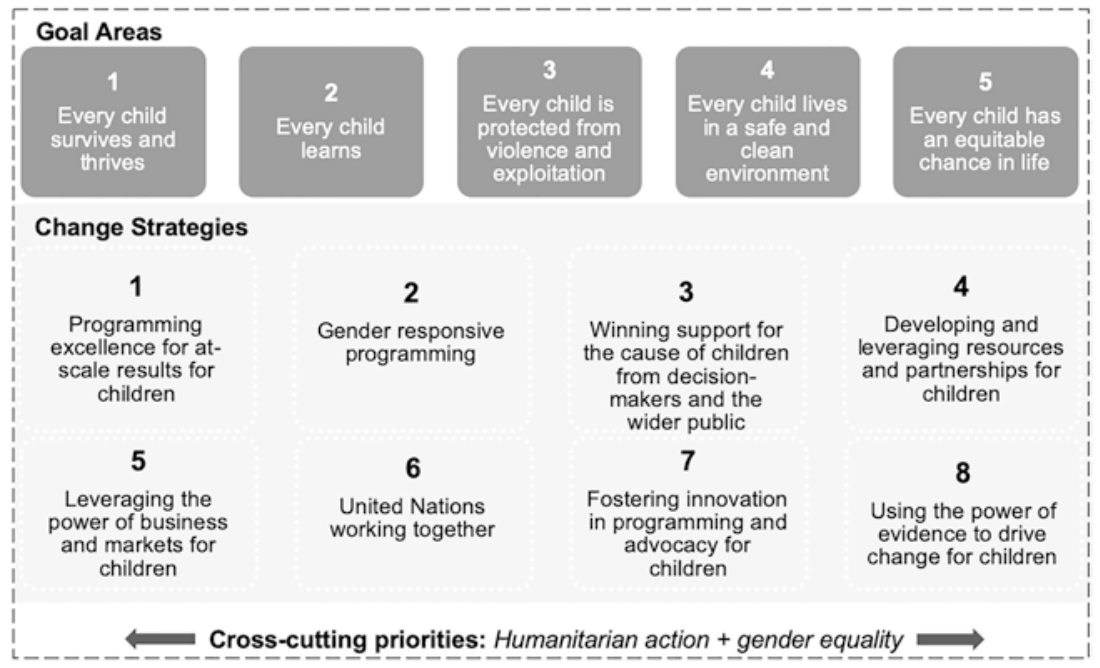

Adapted from: UNICEF. (2018). UNICEF Strategic Plan, 2018-2021: Executive Summary.

Fig. 9.1 UNICEF Strategic Plan 2018-2021. Goal Areas and Change Strategies

environmental factors determining social and behavioral change (UNICEF, 2018). The social-ecological framework (Fig. 9.2) comprises five levels: individual, interpersonal, community, institutional, and policy/enabling environment (UNICEF, 2018). It draws on a wide range of theories to understand determinants of behaviors, detect communication gaps across the levels, and address them with integrated approaches (Gillespie et al., 2016; UNICEF, 2018). The use of the social-ecological model makes EE even more relevant, as EE is often expected to work across different audiences and across the levels of the model.

\section{ENTERTAINMENT-EDUCATION IN UNICEF}

While entertainment formats have been a core feature of UNICEF's development and humanitarian work for decades, the launch of the Meena cartoon character in the early 1990s was a turning point for the organization. Meena, a young girl, became widely popular throughout South Asia and provided a platform to portray girls' aspirations and promote gender equality, girls' rights, and other rights for children. An evaluation of the Meena Communication Initiative in eight countries across South Asia 


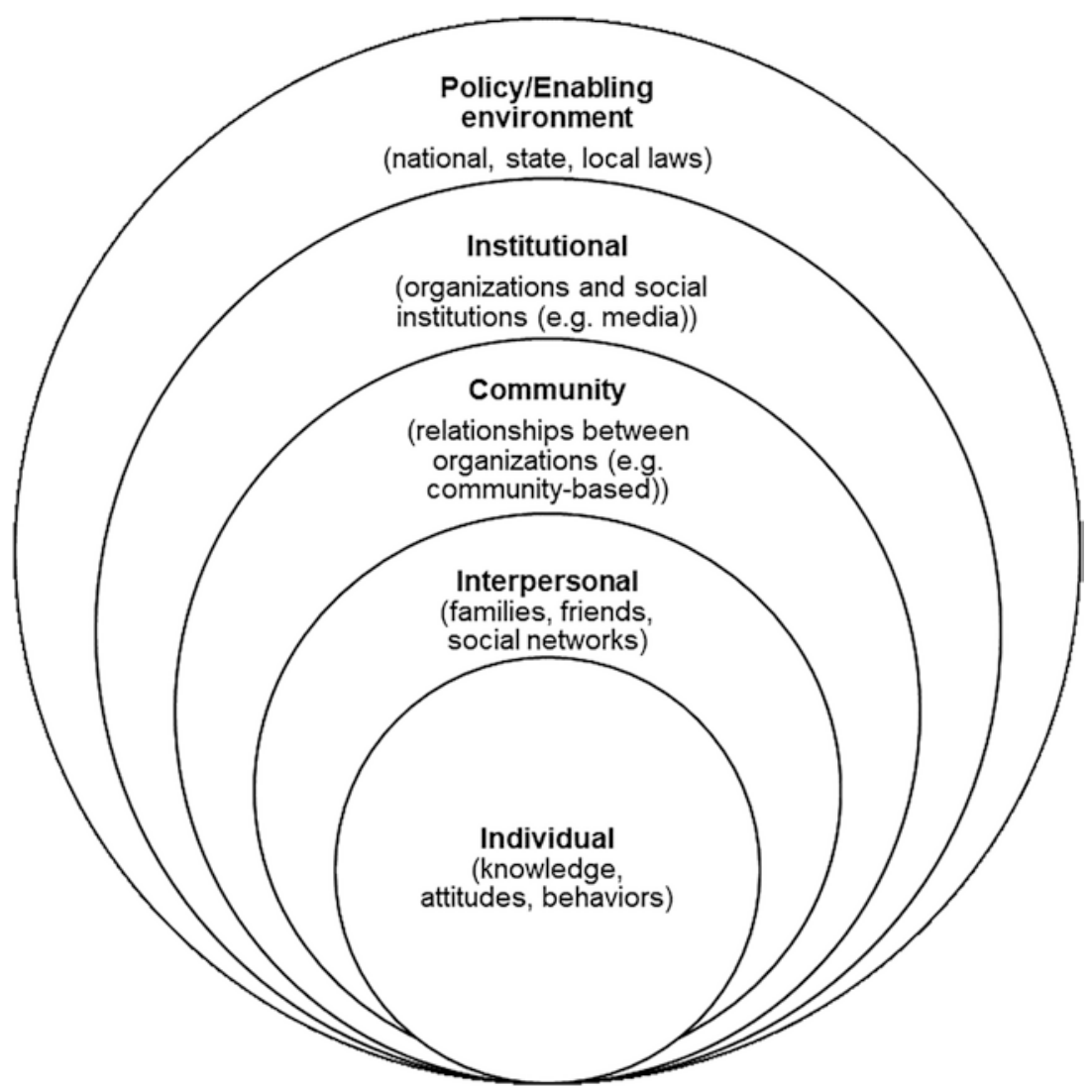

Fig. 9.2 Social-ecological model. (Adapted: UNICEF. (2018). UNICEF 2017 report on Communication for development (C4D). Global progress and country-level highlights across program areas)

documented that Meena reached millions of children, both boys and girls, its cross-country appeal, its contribution to raising awareness about gender equality, and its promotion of life skills such as good nutrition (Chesterton, 2004). Meena's stories, which are still used today in India and Bangladesh, were adapted to different media formats and served as a strong reference for the growing use of EE strategies in UNICEF's development and humanitarian programs, including its replication through a similar character named Sara in East and Southern Africa. 
Over the past decades, building on the success of Meena, UNICEF has used numerous formats, approaches, and partnerships in its EE development programs. For instance, UNICEF supported early EE initiatives such as Soul City in South Africa and Puntos de Encuentro in Nicaragua. UNICEF also has engaged in regional EE partnerships such as Cést la Vie, a TV drama broadcast across West Africa in collaboration with Canal Plus and several regional and international agencies. In collaboration with the MTV Foundation, UNICEF also implemented Shuga, a radio show later developed into a TV series, which promoted HIV prevention. EE formats such as popular theater have been widely used by UNICEF in many countries to address social norms that drive child marriage and female genital cutting. Through collaboration with Nollywood producers, brief drama pieces have been produced and disseminated via mobile phones to promote polio vaccines in hard-to-access areas in Nigeria. Over the years, UNICEF's EE work has operated under three primary modalities. Table 9.1 outlines these modalities and lists relevant and illustrative examples.

An inventory of EE initiatives across UNICEF conducted in 2013 showed that at least $17 \mathrm{EE}$ initiatives were being implemented at the time, with most of those interventions falling in the third modality. In most cases, these EE interventions were part of broader C4D strategies that included other community and interpersonal communication components, the majority of which were driven by social and behavioral theory. For instance, polio video capsules and related content focused on building trust in health care workers among resistant communities (Obregon \& Guirgis, 2017). Cést la Vie focuses on a wide range of health and development issues and regularly models behaviors to challenge, for instance, prevailing social norms about Female Genital Cutting (FMG). This behavior modeling draws on key concepts from social cognitive theory such as self-efficacy.

\section{La Peor Novela}

La Peor Novela ("The Worst Telenovela" which implies that the challenging lives that the main characters experience is the real worst telenovela) is part of a broader C4D strategy which was designed based on the socialecological model. The EE component supports efforts to promote changes in attitudes, norms, and behaviors and contributes to broader development outcomes in areas such as prevention of child marriage and prevention of gender-based violence. The Dominican Republic has experienced 
Table 9.1 Typology of entertainment-education modalities in UNICEF

\begin{tabular}{|c|c|c|}
\hline Modality & Key dimensions & Example \\
\hline $\begin{array}{l}\text { UNICEF-led } \\
\text { EE }\end{array}$ & $\begin{array}{l}\text { UNICEF invests } \\
\text { considerable resources and } \\
\text { takes an active role in the } \\
\text { conceptualization, design, } \\
\text { implementation, and } \\
\text { evaluation. }\end{array}$ & $\begin{array}{l}\text { Kyunki... Jeena Issi Ka Naam Hai } \\
\text { (Because... That's What Life Is), a long } \\
\text { running soap opera nationally broadcast } \\
\text { in India through a partnership with BBC } \\
\text { Media Action and the National TV } \\
\text { Channel Doordarshan with a focus on } \\
\text { health, gender equality, and community } \\
\text { development }\end{array}$ \\
\hline $\begin{array}{l}\text { UNICEF } \\
\text { supported }\end{array}$ & $\begin{array}{l}\text { UNICEF partners with } \\
\text { NGO development and EE } \\
\text { implementing agencies with } \\
\text { less involvement in it. }\end{array}$ & $\begin{array}{l}\text { Cést la Vie (That's life) is a TV soap opera } \\
\text { broadcast across regional and national } \\
\text { African TV networks. It is a program of } \\
\text { Réseau Africain d'Education en Santé, } \\
\text { produced by Keewu Productions in } \\
\text { collaboration with UNICEF, UNFPA, } \\
\text { and other partners. The drama is } \\
\text { broadcast in several languages and } \\
\text { addresses a wide range of health and } \\
\text { development issues. }\end{array}$ \\
\hline $\begin{array}{l}\text { UNICEF } \\
\text { interventions } \\
\text { with EE } \\
\text { components }\end{array}$ & $\begin{array}{l}\text { UNICEF integrates } \\
\text { targeted EE components in } \\
\text { health and development } \\
\text { interventions. They tend to } \\
\text { have shorter duration and } \\
\text { limited scale. }\end{array}$ & $\begin{array}{l}\text { This modality includes a wide range of } \\
\text { initiatives ranging from the use of street } \\
\text { theater to radio and TV shows targeting } \\
\text { youth to the use of brief animated } \\
\text { productions to promote children's rights } \\
\text { or reach populations in hard-to-access } \\
\text { areas. Examples include Shuga, a radio } \\
\text { series to promote HIV Prevention in } \\
\text { collaboration with the MTV Foundation, } \\
\text { UNAIDS, and other agencies; production } \\
\text { of video capsules for promotion of polio } \\
\text { vaccination in Nigeria, in collaboration } \\
\text { with Nollywood producer; use of street } \\
\text { theater in Bangladesh to promote social } \\
\text { norms change related to child marriage. }\end{array}$ \\
\hline
\end{tabular}

substantive economic growth over the past few years, and important investments have been made to improve the conditions of large segments of the population. However, significant inequality and exclusion gaps persist. Protection of children against violence, abuse, and exploitation remains one of the critical challenges for the country. Sixty-three percent of children and adolescents aged 1-14 years are victims of violent 
discipline at home. La Peor Novela was launched in a context where 36\% of young women marry before reaching 18 years, the highest percentage in Latin America and the Caribbean, and where existing social norms tolerate it.

In collaboration with the government of the Dominican Republic, NGOs, and private sector organizations, the soap opera falls under the first category of UNICEF's EE typology. It consisted of two stories divided into five short chapters, each ending with key information on the consequences of early marriage for girls and the country. For example, chapter 1 presents the story of Paola, a young girl who finds early union is a way out of sexual abuse at the hand of her stepfather; Paola's partner then abandons her after she becomes pregnant. In chapter 2, Kenia, a 14-year old girl, is given in early marriage by her mother in exchange for protection and economic stability, yet Kenia is mistreated and eventually kicked out for not meeting the man's expectation. Kenia's disappointed mother does not allow her back in the home, and the episode shows how Kenia's life takes a tragic turn. The goal was to challenge norms supporting early marriage, while at the same time showing that choices to marry early are often influenced by factors such as abuse or parental pressure and should not be judged.

La Peor Novela has been implemented in two distinctive phases. The first phase was the national broadcast of the soap opera which brought social visibility to early unions and shifted society's perceptions about them. The show reached at least 2.3 million people and contributed to greater levels of audience engagement compared to previous online-only campaigns, including an increase in positive comments from $30 \%$ to $63 \%$. Monitoring data showed shifts in perceptions about child marriage, including a $20 \%$ increase (from $63 \%$ to $83 \%$ ) among respondents who stated that "it is wrong, under any circumstances, that girls marry older men," and an $11 \%$ increase among respondents who said that "it is a crime for an adult to have sexual relations with a girl under 18 years of age." However, respondents continued to perceive child marriage as a private matter, tended to hold the parents or the family $(28 \%$ to $62 \%)$ responsible for it, placed little responsibility on the men who engage in child marriage (only 11\%), and did not see the need to intervene in such cases (nearly $50 \%$ ). Similarly, perceptions about the role of men and women, including among adolescents between 12-17 years of age, illustrated gender inequalities that perpetuate early marriage; $92.6 \%$ believe that the main role of females is to be good women and mothers, while $87.2 \%$ believe that the 
main role of men is to be economic providers (UNICEF, 2020). These results led to important dialogue between UNICEF and the government leading to commitments to ending early marriages, including a second phase focused on an EE intervention in schools. The second phase focuses on the development of an EE package that draws on the La Peor Novela episodes to promote prevention of early marriage at scale and with a longterm perspective through the country's schools.

\section{Assessing the Use of Communication Theory in LA PEOR NOVELA}

While the program designers did not explicitly use these theories to develop La Peor Novela, we believe that analyzing it with theory provides important insights to substantiate our argument for greater integration of communication theory into EE. Social cognitive theory and other theories commonly used in EE provide an important basis for understanding some of the cognitive processes underlying individual change, but they do little to explain which narrative approaches are most likely to spark these cognitive processes. For this, theories such as the extended elaboration likelihood model (EELM) and the entertainment overcoming resistance model (EORM) might provide additional clarity. Additionally, we present the concept of "sensemaking" as a framework for understanding the cognitive processes audiences undergo as part of their engagement with EE content.

\section{Extended Elaboration Likelihood Model (EELM) and the Entertainment Overcoming Resistance Model (EORM)}

According to Petty and Cacioppo (1986), the elaboration likelihood model (ELM) posits that individuals process messages through two main channels: central processing which is concerned with attention to the message being presented and peripheral processing which focuses on cues. Persuasive messages sustain an individual's attention while prosocial subtext embedded in the narrative may present desired behaviors. The extended elaboration likelihood model (EELM), which developed from the earlier ELM, helps to identify factors that impact audience members' reception and processing of persuasive messages. For example, Slater and Rouner (2002) have found that "psychological reactance," or a kind of resistance to a message that comes across as overtly persuasive, can 
interfere with an individual's motivation to imitate behaviors. They go on to argue, however, that persuasive narratives lead to increased involvement of the audience in the narrative, and that such "absorption in the narrative may motivate deeper processing of a different kind" (p. 187); narratives can reduce counterarguing and help audiences come to endorse attitudes and behaviors modeled in the narrative. Shrum (2004) similarly finds that this involvement can lessen instances of message resistance.

The Entertainment Overcoming Resistance Model (EORM) goes a step further in detailing the importance of considering counterargument, as it provides a framework to understand aspects of a message that might cause resistance and suggests ways in which EE can mitigate this resistance (Moyer-Gusé, 2008). Message resistance occurs when individuals perceive their choices are threatened while engaging with persuasive messages, which then results in rejection of the message (Buller, Borland, \& Burgoon, 1998). However, stories that present balanced, yet complex situations are able to overcome reactance that stems from this perceived threat to choices (Moyer-Gusé, 2008). Thus, we can see how narrative effects such as reactance, involvement, or transportation can all serve as variables that mediate EE effects (Wendorf Muhamad, 2016).

La Peor Novela provides a good example of how these narrative effects can influence the messages audience take away from the intervention. The various chapters of La Peor Novela show the detrimental effects that not only child marriage but also judgment and stigma can have on the individual. Recognizing the possibility that individuals may not perceive themselves as similar to the characters, and may counterargue (e.g., "that doesn't sound like me," "no one here acts that way"), the producers portray positive, negative, and neutral characters as in Miguel Sabido's original approach. However, unlike the Sabido Methodology, in the case of $L a$ Peor Novela, one of the main characters makes a choice that negatively impacts her life. Clearly, young girls should not be judged for making such decisions as they are influenced by multiple factors; thus, by eliminating potential instances of resistance, audiences are better able to focus on the intended message that child marriage was nonnormative.

Throughout the 10 episodes, audiences are presented with characters who engage in nonnormative behaviors, such as Kenia's mother, but also with characters demonstrating desired behaviors, like the neighbor telling Kenia's mother that she should not send her child off with an older man. Main characters at times express doubts about what to do and the consequences of engaging in or avoiding early marriage are portrayed as well. 
This realistic presentation of a complex social issue is purposeful in that it allows audiences to engage with the material while mitigating reactance that may emerge as a result of fatalistic thinking ("there is no solution to this problem").

\section{Overcoming Reactance Through Character Identification, Transportation, and Sensemaking}

Character identification and transportation are two related narrative concepts that help us understand how viewers relate with the role models portrayed in the intervention. Character identification is the process through which audiences understand the characters' experiences through finding shared attitudes, behaviors, beliefs, values, and/or experiences (Flavell, Botkin, Fry, Wright, \& Jarvis, 1968). Identification involves elaboration on why the character might have made certain choices (Tal-Or \& Cohen, 2010). Cohen (2001) found that character identification involves four dimensions: (1) feelings, (2) thoughts, (3) goals, and (4) transportation to the story. Through character identification, individuals are able to perform identities of others while retaining their own. This in turn allows for parallel processes of observing and internalizing prosocial attitudes and behaviors (Wendorf Muhamad \& Kim, 2020). Transportation, or narrative involvement, is the process in which individuals are absorbed cognitively and emotionally into the story (Green \& Brock, 2000). This process allows individuals to live experiences, instead of just witness the story. Transportation is an effective tool for reducing reactance, because for individuals to be fully immersed in stories, they must temporarily suspend belief (Gilbert, 1991). If the story is entertaining enough, the individual will be willing to discard certain preconceived attitudes or ideological differences with characters (Wendorf Muhamad, 2016).

La Peor Novela attempted to encourage both identification and transportation. Telling the stories of Paolo and Kenia, fictional characters similar in age, gender, and socioeconomic status to the target audience encouraged character identification through perceived similarity. The viewers were then asked by a mix of people from their communities to take the perspective of these characters, as they were subjected to abuse. This perspective taking was further encouraged by narratives that approach the issue from varying perspectives and scenarios that prompt viewers to become immersed by adopting a position within the story. Additional elements such as simplified language, culturally appropriate dialect, accuracy 
of food, dress, and housing further the absorption process. Subtle details, although not central to the story line, enhance this sense of identification and absorption and reduce counterarguing. The prosocial subtext can be more effective and encourage viewers to further identify with the characters and understand their perspectives. Through this perspective taking, identification of shared values, beliefs, attitudes, or behaviors is possible, and viewers are able to assess what possibilities exist, given the circumstance facing the characters. In so doing, audiences are challenged to examine and question stigmatizing attitudes as a new reality unfolds through placing themselves in the experiences of the character.

Sensemaking. Sensemaking helps explain how individuals negotiate their experiences, attitudes, and behaviors. Sensemaking involves audiences rationalizing the characters and their own experiences, so they are understandable (Maitlis \& Christianson, 2014; Maitlis, 2009; Weick, Sutcliffe, \& Obstfeld, 2005; Weick, 1995; Webb \& Weick, 1979). When individuals are confronted with new, confusing, or surprising events, sensemaking can be activated. In the case of EE, viewers are challenged to rationalize and make sense of the experiences of the story characters, which can often be quite different from those of the viewer. According to Blatt, Christianson, Sutcliffe, and Rosenthal (2006), sensemaking operates through ( 1 ) confidence in one's understanding of the situation and (2) the nature (positive or negative) of the relationship with the others in shared experience. Given that EE interventions simulate fictional yet plausible worlds, they provide avenues for the viewers to understand how the characters perceive themselves, their environment, and norms.

La Peor Novela used this approach to help viewers that might not have had experience with child marriage or might have internalized it as normative to understand the topic. By presenting information on its harmful effects and potential solutions, La Peor Novela enables viewers to confront existing norms in a low resistance space, while at the same time understanding how said norms might have been enabled previously.

Sensemaking can also be a productive process to inform formative research when designing an EE intervention, as was the case for La Peor Novela. Younger participants surveyed after exposure to early versions of the EE package were more likely to identify the enacted behaviors as nonnormative, while older ones tended to conform to the dominant normative expectation. More importantly, the data did not show a significant change in normative beliefs after viewing the EE intervention.

What might have caused this response? The intervention's designers attempted to understand this finding via sensemaking, by engaging 
critically with the material presented in La Peor Novela. Although the show provided information at the end of the episode on why the enacted behavior was nonnormative, it did little in terms of portraying prosocial attitudes/behaviors that could be imitated. The team realized that this presentation of a social problem without a solution could, in turn, activate reactance among audience members. In response, the team developed short debriefing videos, presented before and after the soap opera, wherein individuals, demographically similar to the target population, speak directly to the audience. These clips not only provide potential solutions to viewers, but are also based on accepted cultural norms, such as community and togetherness, that might further mitigate any potential rejection of the message.

\section{Lessons Learned and Best Practices}

Our analysis of the La Peor Novela has shown how communication theories can provide insights into the narrative processes that support the social and cognitive change process of $\mathrm{EE}$ and provides important lessons for better integration of communication theory into EE practice. Specifically, the La Peor Novela experience points to some insights that are relevant for practitioners, academics, and researchers who engage in EE interventions, especially in the context of international development programs that organizations such as UNICEF lead or support worldwide.

1. Without adequate integration of theory in EE, designers and producers may not have enough information about how audience members interact with the program content. While integration of theory is often seen as too costly or complex a process for development programs bound by time and resource constraints, in many cases, these perceived costs are outweighed by the benefits. The $L a$ Peor Novela formative research process, for example, demonstrated how applying a sensemaking theoretical lens helped producers avoid the cost of distributing a product that was not sufficiently effective in overcoming audience resistance.

2. Not only is the integration of theory critical, but this analysis has shown how communication theory in particular, as well as critical aspects derived from it such as character identification and transportation, can be powerful tools (both in the formative and evaluation stages) to understand how EE can effect change. We suggest that 
using such narrative and communication theories alongside the social and cognitive theories historically used in EE will provide program planners with more powerful theoretical frameworks with which to approach this work. For example, in La Peor Novela, we see how communication concepts like transportation and identification can help to further understand how the role modeling (which drew on more traditional social cognitive theories) in La Peor Novela positively affects audience. In short, we argue for deliberate and systematic use of communication theories to maximize the power of social and behavioral theories to drive changes. However, doing so will require greater dialogue and sharing between C4D/SBCC program designers, EE producers and creative personnel, EE researchers, managers of development programs, donors, and decision makers to advocate for resource and time allocation for improved integration of communication theory.

3. While our analysis focuses primarily on the integration of communication theory in EE, we also argue that such efforts should be broadened to ensure that communication theory is central to all aspects of communication strategies used in international development beyond EE. Global fora for international development such as the Global Alliance for Social and Behavior Change and the Social and Behavior Change Communication Summit that serve as platforms to advocate for stronger integration of C4D and SBCC in international development should also be leveraged as spaces to more proactively and deliberately address the limited use of communication theory in EE interventions. Moreover, academic and professional communication gatherings where the boundaries of communication theory are also pushed should serve as active platforms to facilitate dialogue between development policy makers and communication practitioners. Lastly, technical tools and guidance that practically translate C4D and EE initiatives into practice should include specific sections that explain and illustrate how communication theory can make a difference both in the overarching aspects of social-ecological models as well as in specific components such as EE interventions. Such focus will ensure that capacity strengthening initiatives in C4D and SBCC and their actual application will effectively draw on the power of communication theory to inform more effective narrative-based interventions for change. 
We would like to close by noting that this analysis has focused on a largely TV-based EE intervention, but the changing media landscape will increasingly call on us to think about EE differently. Historically, EE interventions were most often designed for and studied in the context of traditional media like television or radio (Sabido, 2004). Today we have a much wider variety of communication channels, including digital and mobile technologies, and social media platforms. Stories are no longer contained solely within the confines of the television episode, but storytelling often takes place across a transmedia landscape. While it will continue to be important for EE to draw on radio and television formats, especially in low resource settings, it is also important to look at the role of digital media, including interactive media such as video games and serious games (Wendorf Muhammad et. al., 2019). While considering these new landscapes, it will continue to be important to draw on theory, especially communication theories. In particular, this can be informed by a growing body of communication theory and research for the development of serious games that have evolved rapidly. Relying strongly on theoretical foundations emerging from scholars looking at these new digital, mobile, social media, video games, and transmedia approaches could strengthen efforts to achieve the behavioral and normative changes in EE initiatives undertaken by organizations such as UNICEF.

The authors would like to thank the UNICEF Dominican Republic Country Office, particularly Lilen Quiroga, Communication for Development Officer, and Vianka Oliveros, Communication Officer, who provided access to key resources, materials, and relevant background information.

\section{REFERENCES}

Bandura, A. (1986). Social foundation of thought and action: A social cognitive theory. Prentice-Hall.

Blatt, R., Christianson, M. K., Sutcliffe, K. M., \& Rosenthal, M. M. (2006). A sensemaking lens on reliability. Journal of Organizational Behavior, 27(7), 897-917.

Brown, W. (2013). Promoting health through entertainment-education media: Theory and practice. In R. Obregon \& S. Waisbord (Eds.), The handbook of global health communication (pp. 121-143). Wiley-Blackwell.

Buller, D. B., Borland, R., \& Burgoon, M. (1998). Impact of behavioral intention on effectiveness of message features evidence from the family sun safety project. Human Communication Research, 24(3), 433-453. 
Cardey, S., Garforth, C., Govender, E., \& Dyll-Myklebust, L. (2013). Entertainment education theory and practice in HIV/AIDS communication: A South Africa/United Kingdom comparison. Critical Arts, 27(3), 288-310.

Chesterton, P. (2004). Evaluation of the Meena Communication Initiative. UNICEF Regional Office for South Asia Kathmandu. Retrieved from https:// www.unicef.org/evaldatabase/files/ROSA_2004_800_Meena_Comm_ Initiative.pdf

Cohen, J. (2001). Defining identification: A theoretical look at the identification of audiences with media characters. Mass Communication and Society, $4,245-264$.

Flavell, J. H., Botkin, P. T., Fry, C. L., Wright, J. W., \& Jarvis, P. E. (1968). The development of role-taking and communication skills in children. Wiley.

Gilbert, D. S. (1991). How mental systems believe. American Psychologist, 46, 107-119.

Gillespie, A. M., Obregon, R., El Asawi, R., Richey, C., Manoncourt, E., Joshi, K., et al. (2016). Social mobilization and community engagement central to the Ebola response in West Africa: Lessons for future public health emergencies. Global Health: Science and Practice, 4, 626-646.

Green, M. C., \& Brock, T. C. (2000). The role of transportation in the persuasiveness of public narratives. Journal of Personality and Social Psychology, $79,701-721$.

Johns Hopkins University Health Communication Capacity Collaborative. (n.d.). Social and behavior change communication saves lives. Retrieved from http:// ccp.jhu.edu/wp content/uploads/JHU_Social_and_Behaviour_FULL_ OUTLINES_V2.pdf

Maitlis, S. (2009). Who am I now? Sensemaking and identity in posttraumatic growth. In Exploring positive identities and organizations: Building a theoretical and research foundation. Routledge.

Makanweni, B., \& Salawu, A. (2018). Bridging theory and practice in entertainment education: An assessment of the conceptualization and design of Tsha Tsha in South Africa. Communication, 8(1) https://doi.org/10.1177/ 2158244018758146

Moyer-Gusé, E. (2008). Toward a theory of entertainment persuasion: Explaining the persuasive effects of entertainment-education messages. Communication Theory, 18, 407-425.

Obregon, R. and Guirguis, S. 2017. "Health promotion and communication responses to disease outbreaks - lessons from "Getting to Zero Ebola" and polio eradication". International Union of Health Promotion and Education Global Conference, May, Curitiba, Brazil.

Petraglia, J. (2007). Narrative intervention in behavior and public health. Journal of Health Communication, 12, 493-505. 
Petty, R. E., \& Cacioppo, J. T. (1986). The elaboration likelihood model of persuasion. In Communication and persuasion (pp. 1-24). Springer.

Piotrow, P., Kincaid, L., Rimon, J., \& Rinehart, W. (1997). Health communication: Lessons from family planning and reproductive health. Praeger.

Sabido, M. (2004). The origins of entertainment-education. In A. Singhal, M. J. Cody, E. M. Rogers, \& M. Sabido (Eds.), Entertainment-education and social change: History, research, and practice (pp. 61-74). New York: Routledge.

Shrum, L. J. (2004). The cognitive processes underlying cultivation effects are a function of whether the judgments are on-line or memory-based. Communication, 29(3), 327-344.

Singhal, A., \& Rogers, E. (1999). Entertainment-education: A communication strategy for social change. Lawrence Erlbaum.

Slater, M. D., \& Rouner, D. (2002). Entertainment education and elaboration likelihood: Understanding the processing of narrative persuasion. Communication Theory, 12, 173-191.

Sood, S., Riley, A., \& Alarcon, K. (2017). Entertainment-education and health and risk messaging. Communication. https://doi.org/10.1093/acrefore/ 9780190228613.013 .245

Tal-Or, N., \& Cohen, J. (2010). Understanding audience involvement: Conceptualizing and manipulating identification and transportation. Poetics, $38,402-418$.

Tufte, T. (2008). Fighting AIDS with edutainment: Building on the Soul City experience in South Africa. In J. Servaes (Ed.), Communication for development and social change (pp. 327-346). Sage.

UN Commission on Human Rights. (1990). Convention on the Rights of the Child.

UNICEF. (2018). UNICEF Strategic Plan, 2018-2021: Executive Summary.

UNICEF. (2019). Communication for development (C4D). Supplement to the global annual results reports 2018.

UNICEF. (2020). Cambiando normas de género para prevenir el matrimonio infantil y las uniones tempranas en República Dominicana. La experiencia de monitoreo de una intervencion educativa. Republica Dominicana.

Webb, E., \& Weick, K. E. (1979). Unobtrusive measures in organizational theory: A reminder. Administrative Science Quarterly, 24(4), 650-659.

Weick, K. E. (1995). Sensemaking in organizations. Sage.

Weick, K. E., Sutcliffe, K. M., \& Obstfeld, D. (2005). Organizing and the process of sensemaking. Organization Science, 16(4), 409-421.

Wendorf Muhamad, J. (2016). Beyond passive entertainment: Evaluating the role of active entertainment-education in the prevention of commercial sexual exploitation of children (Doctoral dissertation). 
Wendorf Muhamad, J., \& Kim, S. (2020). Serious games communicative tools for attitudinal and behavioral change. In D. O'Hair \& M. O'Hair (Eds.), Handbook of applied communication research. Wiley.

Wendorf Muhamad, J., Schrier, K., \& Huse, L. K. (2019). Facilitating communicative environments: An exploration of game modalities as avenues for prosocial change. In M. Filimowicz \& V. Tzankova (Eds.), Reimagining communication: Mediation. Routledge.

Open Access This chapter is licensed under the terms of the Creative Commons Attribution-NonCommercial-NoDerivatives 4.0 International License (http:// creativecommons.org/licenses/by-nc-nd/4.0/), which permits any noncommercial use, sharing, distribution and reproduction in any medium or format, as long as you give appropriate credit to the original author(s) and the source, provide a link to the Creative Commons licence and indicate if you modified the licensed material. You do not have permission under this licence to share adapted material derived from this chapter or parts of it.

The images or other third party material in this chapter are included in the chapter's Creative Commons licence, unless indicated otherwise in a credit line to the material. If material is not included in the chapter's Creative Commons licence and your intended use is not permitted by statutory regulation or exceeds the permitted use, you will need to obtain permission directly from the copyright holder. 